\title{
Strategies and structures in verbal fluency tasks in patients with Alzheimer's disease
}

\author{
J. Kessler, ${ }^{1}$ M. Bley, ${ }^{2}$ R. Mielke ${ }^{2}$ and E. Kalbe ${ }^{1}$ \\ ${ }^{1}$ Max-Planck-Institut für neurologische Forschung, Gleueler Str. 50, D-50931 Köln \\ and ${ }^{2}$ Neurologische Universitätsklinik, Köln, Germany
}

Correspondence to: J. Kessler at above address

\begin{abstract}
Reduced word production in verbal fluency tasks is a sensitive indicator for brain damage. Patients with Alzheimer's disease (AD) are supposedly more affected in semantic than in letter fluency, which is probably resulting from partially destroyed structure of semantic knowledge, whereas in letter fluency tasks the patients can use phonemic cues for searching. In this study, 21 patients with probable AD according to NINCDS-ADRDA criteria were examined on a verbal fluency task with F, A, S as initial letters, and a supermarket task. Performances were compared with a control group. Patients with AD showed lower word rate in all tasks than the control group. The difference was most significant in the supermarket task. Both groups produced most of the words in the supermarket task, followed by $S, A$ and $F$. They both showed a percentual likely distribution pattern of items into different supermarket categories. The items of the supermarket task were mostly ranged in clusters (patients with $\mathrm{AD} 70 \%$, control group 83\%). Patients with $\mathrm{AD}$, however, on average, used fewer categories which they also filled with fewer items. In the F, A, S test, patients with AD mainly produced nouns, whereas the control group named nearly twice as many adjectives and verbs. In patients with $A D$ word generation was highly correlated with degree of dementia, free recall of a verbal memory task, and the Token test. Low word production and qualitatively changed output in patients with AD might relate to an inefficient searching strategy, attentional deficits and/or degraded semantic knowledge.
\end{abstract}

Keywords: Alzheimer's disease - Retrieval deficit - Semantic memory - Verbal fluency tasks

This article originally appeared in a modified form in Alzheimer's Research (1997), 3, 59-62.

\section{INTRODUCTION}

In verbal fluency tasks subjects have to produce words under a restricted search condition. They can be limited to semantic classes, such as animals, clothes, what can be bought in a supermarket, or to words beginning with F, A, S, for example. Patients with Alzheimer's disease (AD) (Chertkow and Bub, 1990), Parkinson's disease (Bayles et al., 1993), Chorea Huntington (Monsch et al., 1994) or schizophrenia (Joyce et al., 1996) are significantly reduced in their word rate in comparison with a control group. In most studies patients with $\mathrm{AD}$ have more severe deficits in semantic tasks than in letter fluency tasks.

It has been argued that this finding results from impaired semantic memory, whereas in letter fluency tasks patients rather profit from orientation to phonemic cues. One of the semantic fluency tasks - the supermarket task - has an exceptional position and high relevance in everyday life. Food and most household goods are usually bought at the supermarket. The goods have to be chosen mentally before purchasing.
They are confined in a limited space and pre-assorted in different categories. It can be assumed that the supermarket task is less educationally sensitive than, for example, naming animals. In three publications supermarket fluency tasks were compared with letter fluency tasks (Martin and Fedio, 1983; Ober et al., 1986; Tröster et al., 1989). Qualitative and quantitative differences were observed: moderately demented patients named fewer items, used fewer categories, and named fewer items per category than the control group. Our paper involves a replication of these studies and compares the performance of patients with $\mathrm{AD}$ with letter fluency tasks. The output was analysed with a more elaborate evaluation.

\section{PATIENTS AND METHODS}

Twenty-one patients (12 males, 9 females) with probable AD according to NINCDS-ADRDA criteria (McKhann et al., 1984) and DSM-111-R (DSM-III-R, 
1990) were examined. The mean age was 70.85 years $(\mathrm{SD}=9.7$ years). All patients underwent a detailed neurological and psychiatric examination. Ultrasound examinations of the neck vessels and computed tomography or magnetic resonance imaging of the brain were obtained in each case to rule out haemodynamically significant stenosis of the carotid arteries, ischemic infarcts, hemorrhage and brain tumours. Additionally, the modified Hachinski score of Rosen (1980) was used: only patients with a score of 3 or less were included in the study. The minimum duration of illness was 6 months. The patients' cognitive and mnestic status was determined by a neuropsychological test battery which included a brief version of the Token-test (Orgass, 1982), a verbal selective reminding task with delayed recall (Schaaf et al., 1992), the Rey-Osterrieth figure (Spreen and Strauss, 1991), an orientation test apraxia testing and a fragmented picture test (Kessler $e t$ al. 1993). Dementia severity was quantified by the minimental-state-examination (MMST) (Folstein et al., 1975) and the CDR from Hughes et al. (1982).

Nineteen subjects ( 9 males, 10 females) with no clinical evidence of cognitive-mnestic deficits or neurological disorders served as a control group. Education and profession were comparable with the $\mathrm{AD}$ group.

\section{Verbal fluency tasks}

Supermarket task: The subjects were allotted $60 \mathrm{~s}$ to name different items which can be bought in a supermarket. The verbal responses were recorded. The items were assigned to the following categories: drinks, fruit and vegetable, basic food, grains, meat, detergents and cosmetics, edible household goods, desserts and snacks, other articles. In addition, clusters of at least two consecutive responses that belong to one category (e.g. 'wine, juice') were counted. Responses that do not represent a single item but a group of items (e.g. meat) were registered as 'superordinates'. Furthermore a 'type-token-ratio' that indicates how many words were named more than once was obtained by dividing the types (number of different words produced) by total output. Also, the frequency of each type was counted.

$F, A, S$, test: The subjects were asked to produce as many words as possible beginning with $\mathrm{F}, \mathrm{A}$, and $\mathrm{S}$ in $1 \mathrm{~min}$. Proper names and identical words with different endings (such as 'apple juice, apple pie') were not allowed. The total number of correct words was registered and all words were classified according to word class (nouns, verbs, adjectives/adverbs). In this task, phonological clusters (two or more consecutive responses with the same second phoneme) were counted (e.g. 'fruit, fresh, free'). The type-token-ratio was obtained as described above and the frequency of each type was counted, too.

\section{RESULTS}

\section{Patients with $A D$}

In total, the 21 patients named 302 words in the F, A, S test. The mean word rate of the sum was 14.38; for F: $4.61(\mathrm{SD}=3.38), \mathrm{A}: 3.80(\mathrm{SD}=2.90)$ and $\mathrm{S}$ : $5.95(\mathrm{SD}=3.38)$. In the supermarket task 180 items were quoted, which corresponds to a mean rate of $\overline{\mathrm{x}}=8.57(\mathrm{SD}=4.98)$. In calculating the $\mathrm{z}$-scores as a relative deviation measurement from the control group, the following mean $\mathrm{z}$-scores resulted: $\mathrm{F}=-1.4$ $(\mathrm{SD}=0.81), \mathrm{A}=-1.93(\mathrm{SD}=0.73)$ and $\mathrm{S}=-1.57$ $(\mathrm{SD}=0.66)$. The supermarket task showed the highest discrepancy with a $z$-score of $-4.07(\mathrm{SD}=0.90)$. The type-token-ratio for the F, A, S test was 0.79 and 0.53 for the supermarket test. There was a significant correlation between the verbal fluency tasks, the MMST scores $(r=0.80 ; p=0.0001)$ and CDR scores $(r=-0.75, p=0.0002)$, the error rate of the Token test $(r=-0.62 ; p=0.0032)$ and the free recall rate of the verbal memory task $(r=0.76 ; p=0.0001)$.

\section{Control Group}

The 19 subjects named 722 words in the F, A, S test, which corresponds to a mean word rate of 38 . For the letter $\mathrm{F}$ the mean rate was $11.10(\mathrm{SD}=4.64)$, for $\mathrm{A}$ $11.36(\mathrm{SD}=3.91)$ and for $\mathrm{S} 15.52(\mathrm{SD}=6.11)$. In the supermarket task 579 items were named, which corresponds to a mean rate of $30.47(\mathrm{SD}=5.37)$. The typetoken-ratio was comparable with the patients with $\mathrm{AD}$ 's performance in the $\mathrm{F}, \mathrm{A}, \mathrm{S}$ test $(0.81)$ and in the supermarket task (0.54).

\section{Categorical distribution}

Although the patients with $\mathrm{AD}$ named fewer items in the supermarket task, the percentual distribution of the items in the different categories was similar and highly correlated $(r=0.92 ; p=0.0004)$. Regarding basic food, both groups preferentially quoted fruit, vegetable and meat. In patients with $\mathrm{AD}, 28 \%$ of the items were named in a cluster system of two, and $42 \%$ of the items in a cluster system of more than three. The control group summarized $5 \%$ of the items in clusters of two, and $78 \%$ in more than three cluster systems.

The words of the F, A, S test were categorized into nouns, verbs, adjectives and adverbs. In both groups, functional words like 'for, and', were not mentioned. Patients with $\mathrm{AD}$ demonstrated a high rate of nouns (79.5\%), less verbs $(9.64 \%)$ and adjectives $(10.84 \%)$. The control group named nearly twice as many verbs $(18.63 \%)$ and adjectives $(17 \%)$ as the patients with $\mathrm{AD}$. 


\section{DISCUSSION}

Compared with the control group, the patients with $\mathrm{AD}$ showed a reduced word rate. There were, however, quantitative and qualitative differences between the groups. Both groups showed a similar rank order in their output: in the supermarket task most items were named, followed by S, A, and F, as well as a percentual likely distribution pattern of the items into different categories of the supermarket task. Most of the supermarket items were grouped in clusters. In the F, A, S test they were qualitatively different. In comparison with the patients with $\mathrm{AD}$, the control group used nearly twice as many verbs and adjectives.

The underlying deficit which causes the low performance of patients with $\mathrm{AD}$ in verbal fluency cannot be sufficiently explained by this study. In other studies with different designs it was argued that it could be because of actual loss of semantic information and/or to an impairment in the patients' access to an intact semantic structure (Nebes, 1989). Two main problems arise in the interpretation of the data: the heterogeneity of neuropathology in patients with $\mathrm{AD}$ and the multidimensionality of verbal fluency tasks. Different components, such as imagery, cognitive flexibility, search strategies, working memory, speed of processing, and basic linguistic abilities, must interact to perform successfully in these tasks. The patients with AD's deficits in verbal fluency tasks, which have been reliably observed, may be as a result of the Alzheimer-typical combination of a frontal and temporoparietal cerebal dysfunction. The first rather corresponds to attentional deficits, dysfunction of controlled processing with intact automatic processing (Schneider and Schiffrin, 1977), 'effortful encoding' (Hasher and Zacks, 1979) and impaired 'supervisory attentional system' (Shallice, 1988) whereas the latter is associated with affected linguistic processing and memory processing (Karbe et al., 1989; Heiss et al., 1993; Karbe et al., 1995). In contrast to episodic memory deficits, semantic memory deficits are not universal findings in the early course of $\mathrm{AD}$. Referring to the $\mathrm{AD}$ staging criteria by Braak and Braak (1991), Hodges and Patterson (1995) argue that if patients with $\mathrm{AD}$ had no semantic memory deficits the lesion would be restricted to transentorhinal and limbic structure, whereas patients with semantic deficits should have additional temporal neocortical involvements.

\section{CONCLUSION}

In verbal fluency tasks patients with $\mathrm{AD}$ show quantitative and qualitative differences compared with the control group. The underlying deficit which causes the low performance can not be explained by such tasks and has to be analysed in single case and elaborated neurolinguistic studies.

\section{Acknowledgement}

The authors wish to thank $\mathrm{Mr} \mathrm{H}$. Bönner for his statistical advice and his comments on the draft.

\section{REFERENCES}

Bayles KA, Trosset MW, Tomoeda CK et al. (1993) Journal of Clinical and Experimental Neuropsychology, 15, 547-562.

Braak H and Braak E (1991) Acta Neuropathologia, 82, 239-259.

Chertkow H and Bub D (199) Brain, 113, 397-417.

DSM-III-R, (1990) Diagnostisches und Statistisches Manual Psychischer Störungen. Weinheim: Beltz Verlag.

Folstein MF, Folstein SE and McHugh PR (1975) Journal of Psychiatric Research, 12, 189-198.

Hasher L and Zacks RT (1979) Journal of Experimental Psychology, 108, 356-388.

Heiss WD, Kessler J, Karbe $\mathrm{H}$ et al. (1993) Archives of Neurology, 50, 958-964.

Hodges JR and Patterson K (1995) Neuropsychologia, 33, 441-459.

Hughes CP, Berg L, Danzinger WL et al. (1982) British Journal of Psychiatry, 140, 566-572.

Joyce EM, Collinson SL and Crichton P (1996) Psychological Medicine, 26, 39-49.

Karbe H, Herholz K, Szelies B et al. (1989) Neurology, 39, 1083-1088.

Karbe H, Kessler J, Herholz K et al. (1995) Archives of Neurology, 52, 186-190.

Kessler J, Schaaf A, Mielke R (1993) Fragmentierter Bildertest - ein Wahrnehmungs und Gedächtnistest. Göttingen: Hogrefe Verlag.

Martin A and Fedio P (1983) Brain Language, 19, 124-141.

McKhann G, Drachman D, Folstein MF et al. (1984) Neurology, 35, 939-944.

Monsch AU, Bondi MW, Butters $\mathrm{N}$ et al. (1994) Neuropsychology, 8, 25-30.

Nebes RD (1989) Psychology Bulletin, 106, 377-394.

Ober BA, Dronkers NF, Koss E et al. (1986) Journal of Clinical and Experimental Neuropsychology, 8, 75-92.

Orgass B (1982) Token Test. Weinheim: Beltz Test Verlag.

Rosen WG (1980) Journal of Clinical and Experimental Neuropsychology, 2, 135-146.

Schaaf A, Kessler J, Grond M et al. (1992) Memo-Test. Weinheim: Beltz Verlag.

Schneider W and Shiffrin RM (1977) Psychological Reviews, 84, 1-66.

Shallice T (1988) From Neuropsychology to Mental Structure. Cambridge: Cambridge University Press.

Spreen O and Strauss E (1991) A Compendium of Neuropsychological Tests. New York/Oxford: Oxford University Press: 157-167.

Tröster AI, Salmon DP, McCullough D et al. (1989) Brain Language, 375, 500-513.

(Received 2 December 1996; accepted as revised 23 December 1996) 


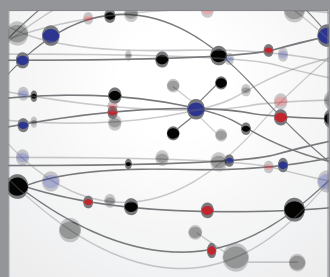

The Scientific World Journal
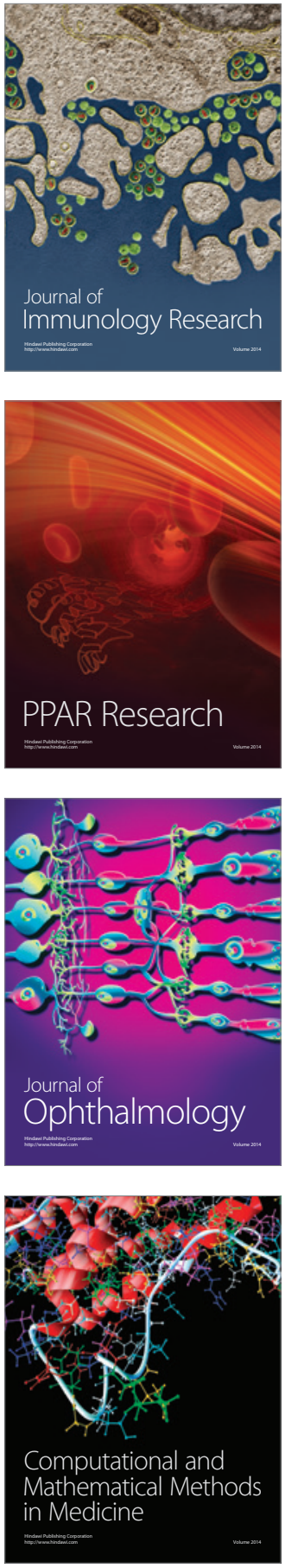

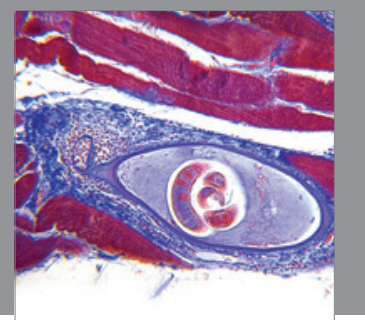

Gastroenterology

Research and Practice
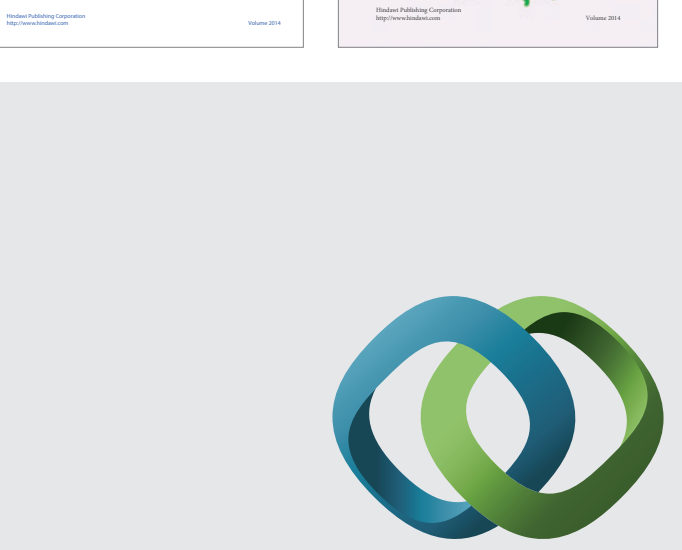

\section{Hindawi}

Submit your manuscripts at

http://www.hindawi.com
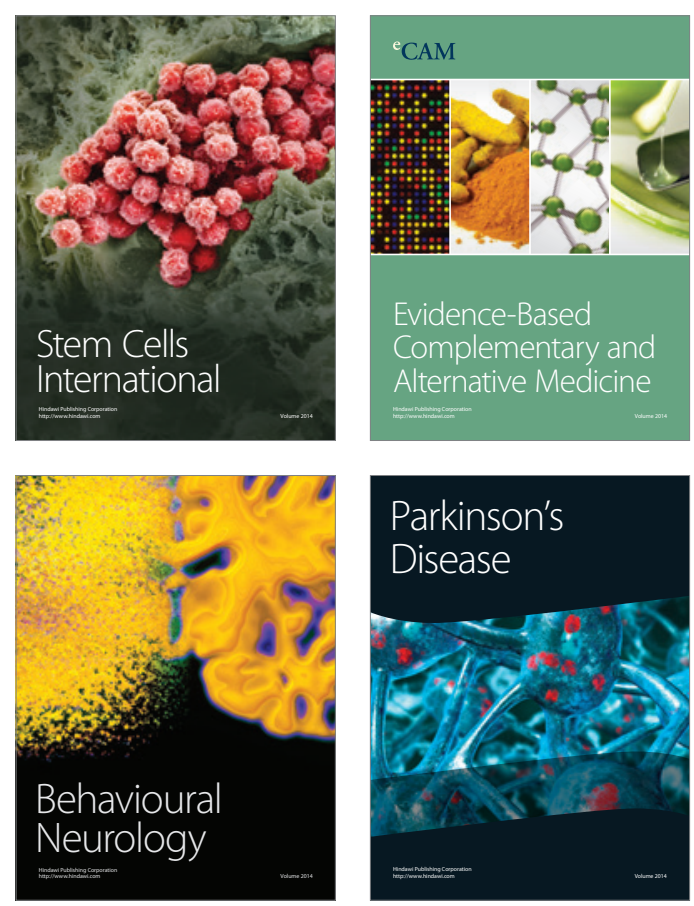

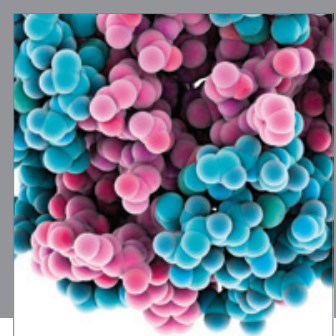

Journal of
Diabetes Research

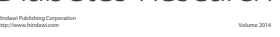

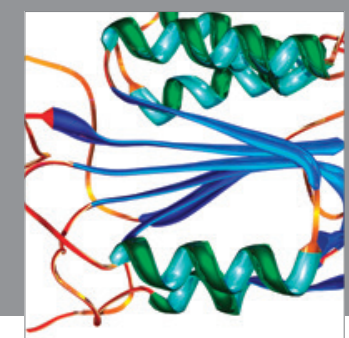

Disease Markers
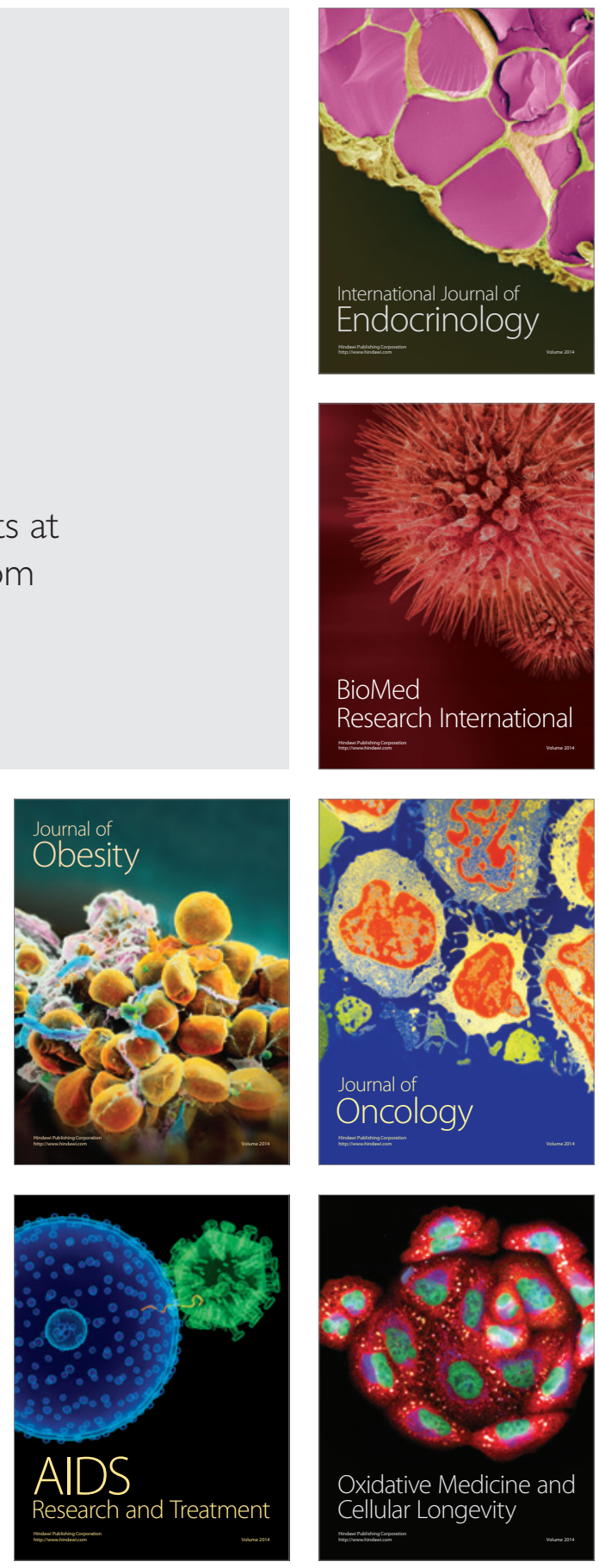